\title{
BMJ Open Protocol for the design of an instrument to measure preadolescent children's self-report of covert aggression and bullying
}

\author{
Helen Jean Nelson, ${ }^{1}$ Garth Edward Kendall, ${ }^{1}$ Sharyn Burns, ${ }^{2}$ \\ Kimberly Schonert-Reichl ${ }^{3}$
}

To cite: Nelson $\mathrm{HJ}$, Kendall GE, Burns S, et al. Protocol for the design of an instrument to measure preadolescent children's self-report of covert aggression and bullying. BMJ Open 2015;5:e009084. doi:10.1136/bmjopen-2015009084

- Prepublication history for this paper is available online. To view these files please visit the journal online (http://dx.doi.org/10.1136/ bmjopen-2015-009084).

Received 15 June 2015 Revised 2 October 2015 Accepted 12 October 2015

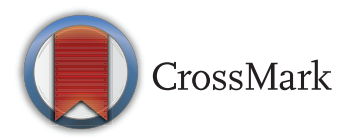

For numbered affiliations see end of article.

\section{Correspondence to} Helen Jean Nelson; helen.nelson@postgrad. curtin.edu.au

\section{ABSTRACT}

Introduction: Covert bullying in schools is associated with a range of academic, social, emotional and physical health problems. Much research has focused on bullying, but there remains a gap in understanding about covert aggression and how to most accurately and reliably measure children's own reports of this behaviour. This paper reviews relevant literature and outlines a research project that aims to develop a selfreport instrument that effectively measures covert aggression and bullying. It is anticipated that this research will result in a standardised instrument that is suitable for exploring preadolescent children's experiences of covert aggressive behaviour. The data collected by the instrument will enhance health and education professionals understanding of covert bullying behaviours and will inform the design and evaluation of interventions.

Methods and analysis: Relational developmental systems theory will guide the design of an online selfreport instrument. The first phase of the project will include a critical review of the research literature, focus groups with children aged 8-12 years (grades 4-6) in Perth, Western Australia, and expert review. The instrument will be explored for content and face validity prior to the assessment of convergent and discriminant validity, internal consistency and testretest reliability.

Ethics and dissemination: The study has been approved by the Curtin University of Human Research Ethics Committee (RDHS-38-15) and by the Executive Principal of the participating school.

\section{INTRODUCTION}

Bullying is widely recognised as a health issue in schools as it is associated with a broad range of social, emotional and physical health problems and poor school achievement. ${ }^{1-3}$ Health problems associated with being a victim of bullying range from loneliness; low self-concept; fear; and somatisation to anxiety, depression and suicidal behaviour. ${ }^{3-5}$
Children who bully others are also more likely to experience poor health and developmental outcomes, such as depression, increased alcohol and substance use, ${ }^{3}$ future school dropout, criminal arrest, and teen parenthood. ${ }^{6}$ Evidence suggests that bullying among school children peaks between the ages of 9 and 13 as children find their social position among their peer group. ${ }^{37}$ At this age and in the school context, support from adults within the school is paramount to nurturing children's emotional well-being as they encounter new social relationships. ${ }^{8}$ In reality, however, adult support is often not forthcoming because adults are simply not aware of bullying behaviour that is deliberately or intentionally hidden. Furthermore, when adults are observing children interacting and actively looking for evidence of bullying it is very difficult for them to differentiate between the playful teasing that is common with children of equal power and the 'systematic abuse of power' that constitutes bullyin$\mathrm{g}$ (ref. ${ }^{9}$, p.174). There is a widely documented need for continuing research into the reliable and valid measurement of bullying that is covert or intentionally hidden. ${ }^{10-12}$ This paper describes the design of research that seeks to develop an instrument to measure the self-report of covert bullying among preadolescent children aged 8-12 years (grades 4-6). It is proposed to include the instrument in a questionnaire to measure covert aggression, bullying, empathy, and related behaviours and attitudes. This will help inform the development of interventions and measures of their effectiveness.

Bullying research has typically focused on physical and verbal behaviour, particularly that of boys. ${ }^{11}$ Recently, it has been emphasised that some children with a good understanding of group dynamics and social 
environments may develop subtle forms of aggressive behaviour that are purposely hidden from adults. ${ }^{13}$ Children involved in covert bullying often hold high social status not only with their peers, but also with their teachers, making it unlikely that it will be recognised or acknowledged. ${ }^{13} 14$ This is a plausible explanation for why bullying continues to be such a major issue in schools despite the policies and programmes that have been widely implemented to prevent it. ${ }^{15-18}$ It is perplexing for many parents and teachers to suggest that children who appear to be well adjusted and successful at school may be causing other children harm. ${ }^{13}$ And yet, it is entirely realistic and understandable as bullying is essentially a means of attaining social dominance. ${ }^{17}$ Harm is caused through the perceived imbalance of power between the perpetrator and the victim, and is perpetuated when adults are either unaware of the behaviour or insensitive to children's reports of bullying. ${ }^{17} 18$

Evidence suggests that for interventions to effectively prevent covert aggression and bullying, they must be based on understanding children's behaviour and experience. ${ }^{10}$ However, the factors which influence this behaviour during preadolescence are not well understood. ${ }^{3} 1117$

Existing research has investigated the different types of behaviour within aggression, including relational aggression, ${ }^{13}{ }^{19}$ and the repeated harm and power imbalance associated with bullying. ${ }^{13}{ }^{20}$ However, there has been inconsistent measurement of bullying behaviour. ${ }^{10}{ }^{11}$ For example, imprecise language is an important issue for research in this field. ${ }^{10}$ While the terms bullying and aggressive behaviour are often used interchangeably, they are different concepts that should be measured differently. ${ }^{11}$ In addition, there is a gap in understanding how to most accurately and reliably measure: (1) the imbalance of power between the perpetrator and the victim; and (2) covert aggression that is intentionally hidden from adults. ${ }^{3}{ }^{10}{ }^{12}$ This limits understanding of factors that contribute to the development of bullying and contributes to difficulty in implementing and evaluating school-based interventions. ${ }^{3} 21$

It is recommended that bullying research begin with the administration of a self-report questionnaire by children as a baseline. ${ }^{1} 112022$ An understanding of the concepts which differentiate bullying from aggression is central to the effective design of an instrument that will measure covert bullying. ${ }^{10} 11$ There are two common features of aggression: (1) an intent to harm the victim physically or psychologically by the perpetrator ${ }^{23}$; and (2) the behaviour is perceived negatively as 'a feeling of hurt' by the victim (ref. ${ }^{10}$, p.278). Bullying happens when aggressive behaviour is carried out repeatedly, in a relationship that has an imbalance of power between the perpetrator and the victim. ${ }^{10}{ }^{11}$ Based on findings from qualitative research with children aged 8-13 years in Australia, Cross et $a l^{13}$ defined covert bullying as any form of bullying 'that is 'hidden', out of sight of, or unacknowledged by adults' (p.xxi). For this study with preadolescent children covert bullying is defined as happening when children behave repeatedly with aggression that is deliberately or intentionally hidden from adults, with the intent of causing harm to a victim, who feels hurt, in a relationship that involves an imbalance of power. Aggression, bullying and covert behaviour form the three scales of the proposed model which was informed by the research ${ }^{10} 1113141923$ (see figure 1).

It is recommended that instruments used to measure bullying behaviour will ideally: assess the intent to harm another by the perpetrator and the report of harm by the victim at the same time ${ }^{11}{ }^{23}$; differentiate between overt physical or verbal behaviour and relational forms of aggressive behaviour ${ }^{14}{ }^{19}{ }^{23}$; differentiate between aggressive behaviour and bullying ${ }^{10}{ }^{11}$; and include a measure of covert behaviour. ${ }^{13}$ The aim of the proposed research will be to facilitate these recommendations by designing an instrument with the intent of measuring seven subscales of behaviour as shown in figure 1 . The subscales are: (1) intent to harm (perpetration), (2) feeling of hurt (victimisation), (3) overt aggression, (4) relational aggression, (5) repetition of behaviour, (6) imbalance of power between the perpetrator and the victim, and (7) covert behaviour. Statistical analysis will be conducted to explore which scales and subscales of behaviour, or factors, can be reliably measured. The following section of the background summary addresses the measurement of aggression, bullying and covert behaviour, the three scales of the proposed model.

\section{Statement of hypotheses}

We hypothesise that: (1) focus group analyses will support the premise that children perceive an increase of hurt when adults are either unaware of, or insensitive to, children's reports of bullying; and (2) exploratory factor analyses (EFA) will provide preliminary support for the seven factors of the proposed model, including covert aggression defined as aggression that is deliberately or intentionally hidden from adults.

\section{Aggression}

Aggressive behaviour is an intentional act towards another with the goal of inflicting harm or injury. Physical aggression is a normal part of development and peaks between the ages of 24 and 48 months, either as a response to frustration or for the purpose of achieving a goal. ${ }^{24}$ As children grow many learn to inhibit physically aggressive behaviour. While most learn prosocial behaviour within nurturing relationships, others may learn subtle forms of aggressive behaviour. ${ }^{24} 25$ Researchers have identified multiple forms of aggressive behaviour and the outcomes predicted by each differ. ${ }^{25}$ Meta-analytic review of aggression research has, however, supported two overall forms of aggressive behaviour. ${ }^{26}$ The first includes physical acts and overt verbal aggression, often termed overt aggression; the second includes hurtful manipulation of relationships causing relational 


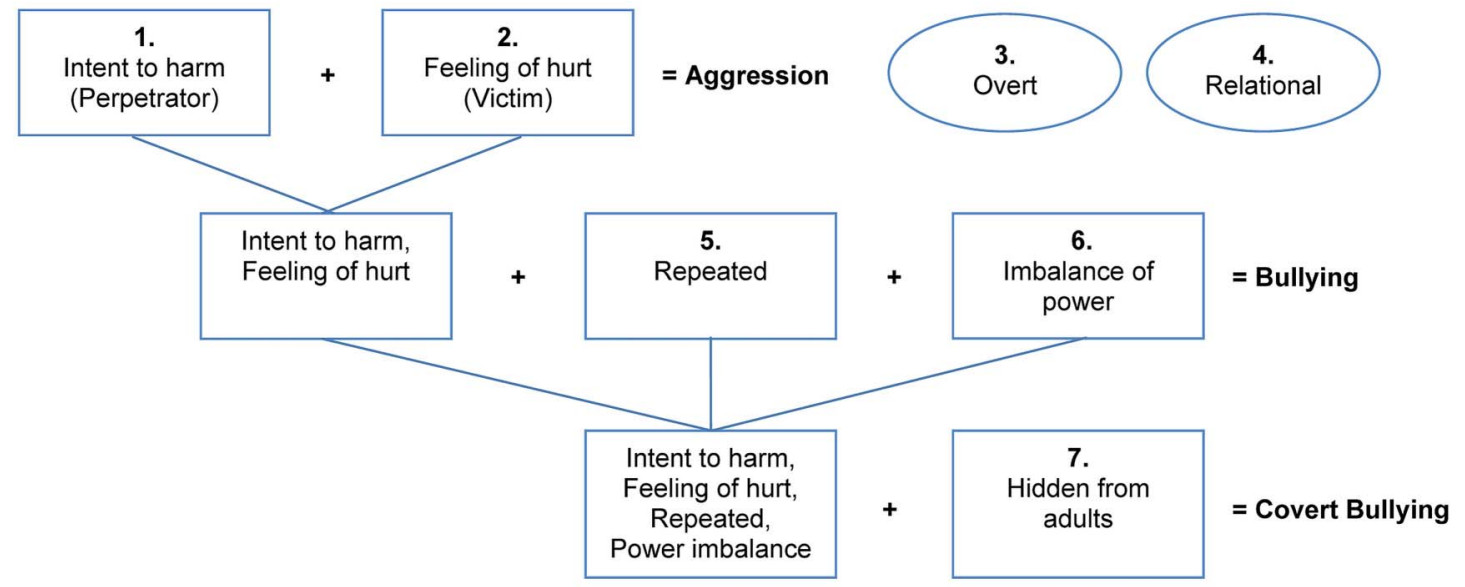

Figure 1 This model, which was informed by the research, ${ }^{10} 1113141923$ proposes a factor structure that will differentiate aggressive behaviour (line 1) from bullying (line 2), and will include a subscale indicating covert behaviour, behaviour that is deliberately or intentionally hidden from adults (line 3). Intent to harm (factor 1) and feeling of hurt (factor 2) are the accepted common features of aggressive behaviour. Aggressive behaviour may be overt physical and verbal behaviour (factor 3 ) or it may be directed at causing harm through social relationships (factor 4). Bullying is a form of aggressive behaviour that is repeated (factor 5), and in which there is an imbalance of power of the perpetrator over the victim (factor 6). At preadolescence, covert bullying (factor 7 ) contributes to harm to the victim while reducing the risk of the perpetrator being seen or found by adults. Statistical analyses will be conducted to explore which factors can be reliably measured.

and social harm. ${ }^{26} 27$ The second form of aggressive behaviour may be termed indirect, ${ }^{28}{ }^{29}$ social $^{30}{ }^{31}$ or relational aggression. ${ }^{32}$

Existing research does not consistently define and measure indirect, social and relational aggression, but each term has a common theme of confronting the social relations of the victim. ${ }^{6}{ }^{26}$ Indirect aggression is generally considered to occur 'behind-the-back' of the victim, the perpetrator causing harm without being identified. $^{28} 29$ Social aggression aims to damage the selfesteem or social standing of another and includes direct or 'face-to-face' forms of negative facial expressions or gestures. $^{30} 31$ Relational aggression is harm caused through hurtful manipulation of peer relationships, encompassing indirect and socially aggressive behaviours. ${ }^{19}$ For the purpose of this research, and consistent with the literature, the term relational aggression will be used to distinguish between overt aggressive behaviour and psychologically aggressive behaviour aimed at causing harm through social relationships. ${ }^{19} \quad 26 \quad 27$ Research suggests that relational aggression may result in more psychological harm than overt behaviour. ${ }^{6} 13$

The Social Experience Questionnaire (SEQ) ${ }^{19}$ is most commonly used to measure overt and relational forms of aggressive behaviour in preadolescent children. ${ }^{1} 33$ The SEQ was first used to measure the self-report of relational aggression by the victim (children in grades 3-6). ${ }^{19}$ Three subscales were found at first to be highly reliable: relational victimisation $(\alpha=0.80)$, overt victimisation $(\alpha=0.78)$ and prosocial recipient $(\alpha=0.77) .{ }^{19}$ Later research found inconclusive reliability of the SEQ self-report over a time period of one and a half years when used with children aged 5-10 years. ${ }^{33}$ Additional qualitative research has been recommended to clarify children's understanding of the items in each subscale. ${ }^{33}$ Furthermore, it has been recommended that the intent to harm another by the perpetrator and the report of harm by the victim are assessed at the same time. ${ }^{10} 1134$

The Adolescent Peer Relations Instrument (APRI) was developed to measure both perpetration and victimisation aspects of aggressive behaviour in adolescents in school grades 7-11 using subscales of verbal, physical and social aggression $(\alpha=0.82-0.93) .^{23}$ The APRI has also been found to be reliable with primary school-aged children in grades 5 and $6(\alpha=00.81-0.90) .{ }^{35}$ Similarly, the Social Bullying Involvement Scales were used to differentiate between the social perpetration of aggressive behaviour $(\alpha=0.93)$ and social victimisation $(\alpha=0.97)$ in a group of adolescents aged 11-16 years. ${ }^{36}$ These authors have proposed that future research include measures of verbal and physical aggression, and empathy. ${ }^{36}$ Measuring perpetration and victimisation of different types of aggressive behaviour, including physical and relational aggression, will contribute to understanding the factors that influence behavioural development at this age. ${ }^{7} 37$

\section{Bullying}

Aggressive behaviour not only occurs in different forms, it serves different functions or purposes. Aggressive behaviour may be a reactive response to perceived threat. $^{38}$ Reactive aggression is associated with poor regulation of emotions and internalising symptoms. ${ }^{27} 38$ Alternatively, aggression may be proactive with the purpose of obtaining a goal, for example, social dominance. $^{27} 39$ Proactive aggression is associated with high levels of callousness, the ability to regulate emotions, a lack of remorse for the harm done to others and a lack 
of empathy. ${ }^{27} 38$ When proactive aggression is a strategic and goal-oriented behaviour, it is regarded as bullying. ${ }^{10} 4041$ The perpetrator, for his or her own benefit, exploits an imbalance of power to dominate the victim repeatedly and in an unwelcome way, resulting in harm or disadvantage to the victim. ${ }^{23}$ Furthermore, bullying is understood to occur as a group process. ${ }^{41}$ The main perpetrator is likely to have a powerful position within his or her peer group, termed the in-group, with a social network of children to assist and defend him or her in the perpetration of harm to another. ${ }^{41}$

There are many reasons why bullying remains a major issue in schools despite the widespread implementation of comprehensive whole-of-school interventions. ${ }^{42} 43$ While it is argued that bullying behaviour can never be totally eliminated, many students, teachers, parents, researchers and policymakers agree that more can be done to manage it and reduce the harm that it causes. From a research point of view, there are major issues associated with the inconsistent use of terminology in instruments that are commonly used to measure bullying behaviour, including differing definitions of bullying. ${ }^{3} \quad 10 \quad 11 \quad 44 \quad 45$ For example, many self-report instruments that measure bullying do not specify how bullying is differentiated from aggression. In addition, there is a gap in understanding how to effectively measure the behavioural component of a power imbalance between the perpetrators and the victims of bullying. ${ }^{11}$ Furthermore, the accuracy of self-reported bullying is unknown and agreement between different informants is low. ${ }^{26}$ The value of self-report may be limited by bias, especially when teachers, parents and peers are not aware that bullying is taking place. ${ }^{45}$ Thus, despite many developments over the past 50 years of bullying research, the factors that influence the development of bullying are not well understood. ${ }^{34}$ The following section reviews the measurement of perceived power imbalance by the victim, a proposed key to increasing the accuracy of bullying assessment. ${ }^{11} 203446$

\section{Power imbalance}

Without a report of power imbalance by the victim, there is likely to be an artificially high correlation between bullying perpetration and victimisation as well as between aggressive behaviour and bullying. ${ }^{11}$ Although perpetrators might report on aggressive behaviour to themselves, in some cases it may be reactive aggression in response to being hurt rather than the proactive aggression that is considered part of bullying. Such perpetrators will, however, still report that they have been exposed to aggressive behaviour even though they are dominant in terms of power, resulting in increased correlations between behaviours. For example, when asked why they bullied other students in a qualitative study $(n=51)$ all indicated they bullied others because they were provoked in some way. For some students, this was reactive as a result of being bullied; however, these bully victims often targeted other children to gain a sense of power. $^{47} 48$ Ideally, research will differentiate between three outcome groups: victim, perpetrator and bully victim based on self-report of power imbalance. ${ }^{11} 46$ The aim of including these outcome groups is to address the overlap between aggressive behaviour and bullying, between perpetration and victimisation, and to give more clarity to the different behaviours within these groups. ${ }^{11}$ Understanding these behaviours is important because the behavioural and health outcomes differ for each group, with the poorest outcomes in the bully victim group. 32049

Reviews of bullying research have recommended that factors associated with power imbalance are likely to include physical strength, group size, older age, popularity, smartness in schoolwork and differences in selfconfidence. $^{114546}$ There is, however, a need to continue investigating the method for measuring aggression in comparison to bullying, including the use of specific individual items to assess power imbalance within selfreport. $^{11} 204650$ For example, victims' perception of power imbalance has been measured using individual items to ask how popular, smart in school and physically strong the other person was. ${ }^{20}$ The authors reported test-retest stability $(\mathrm{r}=0.80-0.83, \mathrm{p}<0.001)$, but concluded that 'smart' may not be a beneficial word to assess power imbalance. ${ }^{20}$ Similarly, the perception of power imbalance may differ by gender. Physical size and group size were found to be significant individual predictors of threat appraisal for boys $\left(\mathrm{R}^{2}=0.074, \mathrm{p}<0.01\right)$, whereas physical size and popularity power imbalance predicted poorer function for girls $\left(\mathrm{R}^{2}=0.075, \mathrm{p}<0.01\right) .{ }^{46} \mathrm{~A}$ limitation of the study was the reliability of the measure of threat appraisal $(\alpha=0.63)$. The authors proposed further research to assess types of power imbalance by gender, ethnic group, socioeconomic status (SES) and success in romantic relationships. ${ }^{46}$ Phase 1 of the proposed research will use focus groups to explore children's perception of what influences and protects against power imbalance to determine relevant language and question structure. In addition, covert behaviour as a source of harm will be explored. Covert behaviour is discussed in the following section.

\section{Covert behaviour}

Covert behaviour as a source of influence in bullying is little understood, in part because covert aggression and bullying are not clearly or consistently defined in the literature. Crick and Grotpeter ${ }^{19}$ differentiate relational aggression from overt physical and verbal aggression, suggesting that relational aggression is considered to be covert behaviour. Others have used the term 'covert' as an alternative to the term 'indirect' when referring to a victim who is unaware of the identity of the perpetrator. $^{365152}$ Such categories of direct versus indirect social or relational aggression, however, are not supported in comprehensive empirical analyses. ${ }^{25}{ }^{36}$ Current research discusses relational aggression as a specific type of indirect aggression that may be both overt and covert. ${ }^{53}$ 
Furthermore, beyond relational aggression, children's understanding of covert aggression includes physical and verbal behaviour, ${ }^{13}$ a view supported by an expert panel of researchers. ${ }^{34}$ In qualitative research with children ( $\mathrm{n}=85$, school grades $4,6,7$ and 8 ), it was found that while covert is not a term that would be used by children, it adequately describes behaviour that is not seen or acknowledged by adults. ${ }^{13}$ This research underscores the point that children's perspectives are crucial as it is children who have the current lived experience of bullying at school. ${ }^{54}$ The harmful effects of aggressive behaviour and bullying are compounded when adults either do not see or fail to acknowledge the behaviour. ${ }^{156}$

Covert behaviour is a potential influence within power imbalance. To this end, children have reported that one way of hurting others without being seen by the teacher is to 'lie to the teacher'(ref. 13, p.149). The group nature of bullying may contribute to harm through covert means as members of the in-group assist and defend the perpetrator. ${ }^{41}$ Targets of covert aggression in middle childhood are likely to remain unidentified when there is uncertain evidence of harm and the source is not clearly identified, for example, when the in-group of the bully participates in a lie. ${ }^{52} \quad 57$ Furthermore, children with leadership skills and a good understanding of social situations may be covertly aggressive, but seen by teachers as mature and socially able. ${ }^{135}$ The findings of one study showed that even at preschool age, when much aggression is visible to teachers $(n=60)$, verbal aggression was positively associated with teacher-rated prosocial behaviour, $r(26)=0.43$, $\mathrm{p}<0.05$, and with teacher-rated peer acceptance for girls, $\mathrm{r}(26)=0.68, \mathrm{p}<0.001 .{ }^{59}$ It has been proposed that the teacher's understanding of harm caused to the victim is masked when the perpetrator holds high social status. ${ }^{57}$

Elder(ref. 60, p.9) talks of 'the maturing experience of working through the pain and confusion of life'. Importantly, this comment is framed within a life-course perspective and understood through the links between people who are important in the child's life. Children's perception of support from adults and connectedness with peers at school are key 'resources' in middle childhood. ${ }^{8}$ Understanding the development of covert aggression in childhood is important for supporting the development of prosocial behaviour. ${ }^{61}$ As previously mentioned, poor agreement between informants has been a common research finding. ${ }^{26}{ }^{42}$ This is to be expected when covert bullying is deliberately hidden from teachers and perpetrators give socially desirable responses. Despite widespread acknowledgement that bullying research will ideally include measurement from multiple informants to reduce bias, child self-report is recommended as a starting point. ${ }^{49}{ }^{62}$ Self-report allows victims of covert bullying to report on their own perceived experience. ${ }^{11}$ For this reason, this research will begin with the development of a self-report measure as a baseline, with the intention of the later inclusion of peer, teacher and parent report instruments. ${ }^{34}$
To the authors' knowledge, there are no self-report measures of aggression and bullying that include each of the defined elements of: intent to harm, feeling of hurt, physical and relational aggression, repetition, power imbalance, and covert behaviour that is deliberately or intentionally hidden from adults. An instrument that provides for children to report on their own experience of covert aggression and bullying will contribute to a greater understanding of the harm that children cause to others and their reasons for doing so, as well as helping to inform the design and evaluation of prevention and intervention strategies. ${ }^{27}$ The ultimate goal is to reduce covert aggression and bullying by bringing it to the attention of students, parents, teachers and other members of a school community.

\section{METHODS AND ANALYSIS}

\section{Research objectives}

This study aims to work with children to develop an online self-report measure of covert aggression and bullying for upper primary school-aged children, and to validate the instrument. The research objectives are: (1) to identify appropriate questions to use in a selfreport instrument that measures aggression and bullying, including covert aggression among preadolescent children (purposive sample, $n=70$ ); and (2) to establish the test-retest reliability, and convergent and discriminant validity of a new instrument designed to measure covert aggression and bullying (purposive sample, $n=140$ ).

\section{Study design}

Instrument development will consist of qualitative and quantitative methods and will be conducted within a theoretical framework of relational developmental systems theory. ${ }^{63}$ Phase 1: Focus groups with children from grades 4-6 will inform the development of the instrument, in conjunction with a critical review of the literature and instruments. Preadolescent children, as members of the target population, are considered 'experiential experts' (ref. 55, p.38). The perspectives of children are therefore a critical part of the development, evaluation and validation of the measure. ${ }^{54} 55$ Phase 2: The instrument will be completed in online format by a purposive sample of students from grades 4-6 (812 years). Quantitative analysis will include EFA, internal consistency, convergent and discriminant validity, and test-retest reliability. Phase 3: A subsequent quantitative study will be conducted with a larger sample of children to further evaluate the model for fit, interpretability, strength and statistical significance, and to assess the criterion validity of the new instrument. This paper focuses on phases 1 and 2 of the proposed research.

\section{Research setting}

Phases 1 and 2 of the study will comprise a purposive sample of students enrolled in grades 4-6 at one independent school in the Perth metropolitan region of Western Australia $(n=210)$. The population in this fee 
paying school is represented by families from a wide range of cultural and ethnic backgrounds who bring to the school an influence of educational advantage because of the parents own level of education and occupation. This is reflected by the 2012 Index of Community Socio-Educational Advantage (ICSEA) value for the school of 1073 , placing it within one SD above the median of socioeducational advantage in Australia. ${ }^{64}$ Bullying occurs across sociodemographic levels and the middle class represents the greater concentration of people in Australia, the focus on the middle class therefore promotes a normative perspective to the research. ${ }^{65} 66$ The school has three classrooms in each grade. Children will be purposefully selected from one classroom in each grade 4,5 and 6 $(\mathrm{n}=70)$ for focus groups in phase 1 of this study. Phase 2 of the study will comprise a purposive sample of students from the remaining two classrooms of each grade 4,5 and $6(\mathrm{n}=140)$. To avoid a potential testing effect, students from classrooms that participated in phase 1 will not be invited to participate in phase 2. Active written consent will be obtained from parents, and written assent will be obtained from children prior to data collection.

\section{Phase 1: instrument development}

This study will use relational developmental systems theory as the theoretical framework. This theory represents development as a result of mutual 'person $\leftrightarrow$ context relations', indicating that all levels of development are integrated within: neurobiological and physiological processes; social relationships; physical processes; ecology, culture and history(ref. 63, p.374). This is an important consideration in research design, which must allow for the context of people's life, as it is lived in their own environment and historical period, to be adequately represented. ${ }^{67}$ The discovery phase of instrument design will be informed by children because children best understand their own experience. ${ }^{68}$

\section{Literature review}

A critical review of the literature will be undertaken to identify existing self-report tools and instrument items that measure each of the seven subscales of behaviour as previously outlined (see figure 1). Psychinfo, MEDLINE and Science Direct databases will be used. The search will include combinations of the following terms: aggression, bullying, covert, relational, indirect, social, report, instrument, childhood, pre-adolescence. Items relevant to each of the subscales will be identified and listed, along with the reported reliability of each item. The following limits will be applied to the search: peer-reviewed journal, human, English language, tests and measures, 6-12 years. The initial review will include publications between 1995 and 2015 and a manual reference list search will be conducted to locate original articles where relevant. Adult-focused scales will be excluded.

\section{Focus groups}

A purposive sample of children aged 8-12 will be asked of their perception of aggression and bullying through a series of focus groups. The aim of the focus groups will be to clarify issues experienced by children, to explore children's understanding of power imbalance and of bullying that is hidden from adults, and to clarify the language children use. Three focus groups will be conducted, it is anticipated that each group will include six to eight children with equal numbers of males and females. ${ }^{69}$

Focus group data will be audio taped, transcribed verbatim and will be reviewed by two researchers, one who has extensive experience in this field, to maintain dependability and determine credibility. ${ }^{70}$ Descriptive codes will be generated, and words and phrases will be explored to elicit shared meanings and perceptions across interviews using a thematic analyses approach. Themes that are commonly presented by children will be identified. The content of existing scales will then be adapted to be consistent and relevant to the findings of the focus groups, and incorporated into the design of the instrument. The qualitative data will be managed using software package NVivo V.10.

\section{Expert review}

A panel of people with expertise in the areas of psychology, education, health promotion, behavioural research and statistics will review the questions in each subscale. For content validity, a minimum of seven experts will be consulted. ${ }^{71}$ The Content Validity Index ${ }^{72}$ will be used to rate item relevance and clarity and the relevance of each subscale.

\section{Instrument format}

The instrument will be completed as an anonymous and confidential self-report of children's own behaviour using an online survey format. Perpetration of bullying may be under-reported by self-report and this needs to be considered when framing research design. ${ }^{12}$ There is little consensus on the influence of social desirability bias on children's own report of bullying others; ${ }^{50} 73$ however, Ahmad and Smith ${ }^{74}$ found that children were more likely to report bullying others by anonymous self-report questionnaire than when they were identified by name. Anonymous self-report is similarly recommended by Rigby ${ }^{75}$ because children may be unwilling to identify themselves as victims or perpetrators of bullying.

\section{Instrument pretest}

Face validity will be assessed by recruiting a purposive sample of children from the target group $(n=10)$ to complete the instrument and to comment on the language, clarity, relevance of the questions and ease of use of the instrument. ${ }^{76}$ Personal feelings or concerns regarding participation in the completion of an online questionnaire regarding bullying will also be explored. 
The wording of items will be changed as indicated. The resulting measure will then be reviewed by another purposively selected group of children $(n=10)$, the process will continue until the language, content and reading ease of the instrument are considered acceptable by the researchers.

\section{Phase 2: construct validity and reliability testing of the proposed instrument}

The self-report instrument will initially be administered to students from one primary school as previously described. EFA will be used to determine which questions within the instrument fit different subscales of behaviour.

\section{Sample size}

Recommendations of sample size for EFA vary between 10 per variable (mid range) and 20 per variable (upper range) ${ }^{77}$ Each factor or subscale of behaviour represents one variable; therefore, for the seven subscales being explored a minimum of 70 participants will represent the midfield of the proposed ratios and 140 students will represent the upper range of 20 children per variable.

\section{Data collection}

The online instrument will be completed in a classroom using Qualtrics online questionnaire software. The researcher will administer the instrument. To ensure confidentiality during administration, children will be seated at a distance from each other and asked not to talk while completing the instrument. Children will be informed that there are no right or wrong answers, will be assured that their answers will be anonymous ${ }^{75}$ and will not be seen by their parents, peers or teachers. ${ }^{36}$ There is a degree of homogeneity associated with SES within schools in the Perth metropolitan region of Western Australia; SES will therefore be recorded by the ICSEA value alone, supporting the anonymity of data collection. ${ }^{78}$

\section{Analysis}

The first step in data analysis will be to conduct a split-half test to assess the consistency of children's responses. ${ }^{79}$ The second step will be to find initial subscales of behaviour, or factors. ${ }^{77}$ The Pearson correlation coefficient $(r)$ between variables will be calculated to find items that have a correlation over 0.30 indicating items that share enough properties to be potential measures of the same factor. The initial construct validity of the instrument will be established through EFA; the fit of items to relevant subscales will be assessed and decisions made on items to be discarded. ${ }^{80}{ }^{81}$ Convergent validity will be supported when items that are similar or strongly correlated load onto the same factor. ${ }^{81}$ Discriminant validity is the extent to which each factor or subscale is well differentiated and will be supported if theoretically different constructs are not highly intercorrelated. ${ }^{81}$ The results will be interpreted to give names to each subscale. The fourth step will assess the internal consistency of the instrument and its subscales using Cronbach's $\alpha$, an $\alpha \geq 0.7$ will be considered adequate. ${ }^{82}$ In the fifth step, the instrument will be administered to the same children 2 weeks after the initial questionnaire for assessment of test-retest reliability. Spearman's $r$ will be calculated; a correlation coefficient between 0.7 and 1.0 will indicate agreement between scores (reliability). Data analysis will be conducted using M-Plus. $^{23}$ Questionnaires with missing data will be excluded from the analysis.

\section{ETHICS AND DISSEMINATION}

Prior to participation in the study, informed written consent will be obtained from parents and informed written assent will be obtained from each participating child. Children will be able to withdraw from the research at any time without negative consequence. ${ }^{83}$ The school psychologist will be available for children to be referred to if they are distressed by the discussion in the focus groups, or if they become distressed during completion of the instrument. A de-identified report of study findings from phase 1 and a report of findings from phase 2 will be given to the School Executive for dissemination to families and staff. Results will also be disseminated through conference presentations and peer-reviewed journals.

\section{Author affiliations}

${ }^{1}$ School of Nursing, Midwifery and Paramedicine, Curtin University, Perth, Western Australia, Australia

${ }^{2}$ School of Public Health and Collaboration for Evidence, Research and Impact in Public Health, Curtin University, Perth, Western Australia, Australia

${ }^{3}$ Educational and Counselling Psychology, and Special Education, University of British Columbia, Vancouver, British Columbia, Canada

Acknowledgements The authors are grateful to Dan Olweus who has given permission to use and modify the Olweus Bullying Questionnaire; and to Roberto Parada, the author of the Adolescent Peer Relations Instrument who has given permission for his scale to be used in this research.

Contributors HJN conceived of the study in consultation with GEK, SB and KS-R, participated in its design, and drafted the manuscript. GEK and SB contributed to the conception and design of the study, writing and revision of the manuscript. KS-R supported HJN with resources and advice during the conception, design, and writing of the study protocol and reviewed the manuscript.

Competing interests None declared.

Ethics approval Curtin University Human Research Ethics Committee (RDHS-38-15), and from the Executive Principal of the participating school.

Provenance and peer review Not commissioned; externally peer reviewed.

Data sharing statement This research is being undertaken by HJN for her doctoral studies. GEK and SB will also have access to research data. Additional unpublished data should be sought from HJN by email.

Open Access This is an Open Access article distributed in accordance with the Creative Commons Attribution Non Commercial (CC BY-NC 4.0) license, which permits others to distribute, remix, adapt, build upon this work noncommercially, and license their derivative works on different terms, provided the original work is properly cited and the use is non-commercial. See: http:// creativecommons.org/licenses/by-nc/4.0/ 


\section{REFERENCES}

1. Card NA, Hodges EVE. Peer victimization among schoolchildren: correlations, causes, consequences, and considerations in assessment and intervention. Sch Psychol Q 2008;23:451-61.

2. Landstedt E, Persson S. Bullying, cyberbullying, and mental health in young people. Scand J Public Health 2014;42:393-9.

3. Moore SE, Norman RE, Sly PD, et al. Adolescent peer aggression and its association with mental health and substance use in an Australian cohort. J Adolesc 2014;37:11-21.

4. Nikiforou M, Georgiou SN, Stavrinides P. Attachment to parents and peers as a parameter of bullying and victimization. J Criminol 2013;2013:e484871.

5. Vernberg EM, Nelson TD, Fonagy $P$, et al. Victimisation, aggression and visits to the school nurse for somatic complaints, illness, and physical injuries. Pediatrics 2011;27:842-8.

6. Xie H, Swift DJ, Cairns BD, et al. Aggressive behaviors in social interaction and developmental adaptation: a narrative analysis of interpersonal conflicts during early adolescence. Soc Dev 2002;11:205-24.

7. Williford A, Boulton AJ, Jenson JM. Transitions between subclasses of bullying and victimization when entering middle school. Aggress Behav 2014;40:24-41.

8. Oberle E, Schonert-Reichl KA, Guhn M, et al. The role of supportive adults in promoting positive development in middle childhood: Liu A population-based study. Can J Sch Psychol 2014;29:296-316.

9. Lester L, Dooley J, Cross D, et al. Internalising symptoms: an antecedent or precedent in adolescent peer victimisation. Aust $J$ Guid Couns 2012;22:173-89.

10. Bovaird JA. Scales and surveys: Some problems with measuring bullying behaviour. In: Jimerson SR, Swearer SM, Espelage DL, eds. Handbook of bullying in schools: an international perspective. New York, NY: Routledge, 2010:277-92.

11. Olweus D. School bullying: development and some important challenges. Annu Rev Clin Psychol 2013;9:751-80.

12. Shaw T, Dooley JJ, Cross D, et al. The Forms of Bullying Scale (FBS): validity and reliability estimates for a measure of bullying victimization and perpetration in adolescence. Psychol Assess 2013;25:1045-57.

13. Cross D, Shaw T, Hearn L, et al. Australian Covert Bullying Prevalence Study (ACBPS). Child Health Promotion Research Centre: Edith Cowan University, Perth. 2009. http://deewr.gov.au/ bullying-research-projects\#australiancovert-bullying-prevalence (accessed 2 Apr 2013)

14. Archer J, Coyne SM. An integrated review of indirect, relational, and social aggression. Pers Soc Psychol Rev 2005;9:212-30.

15. Merrell KW, Isava DM, Gueldner BA, et al. How effective are school bullying intervention programs? A meta-analysis of intervention research. Sch Psychol Q 2008;23:26-42.

16. Srabstein JC, Leventhal BL. Prevention of bullying-related morbidity and mortality: a call for public health policies. Bull World Health Organ 2010;88:403.

17. Liu J, Graves N. Childhood bullying: a review of constructs, contexts, and nursing implications. Public Health Nurs 2011;28:556-68.

18. Ayers SL, Wagaman MA, Geiger JM, et al. Examining school-based bullying interventions using multilevel discrete time hazard modeling Prev Sci 2012;13:539-50.

19. Crick NR, Grotpeter JK. Children's treatment by peers: victims of relational and overt aggression. Dev Psychopathol 1996;8:367-80.

20. Felix ED, Sharkey JD, Green JG, et al. Getting precise and pragmatic about the assessment of bullying: the development of the California Bullying Victimization Scale. Aggress Behav 2011;37:234-47.

21. Cook CR, Williams KR, Kim TE, et al. Predictors of bullying and victimization in childhood and adolescence: a meta-analytic investigation. Sch Psychol Q 2010;25:65-83.

22. Jimerson SR, Swearer SM, Espelage DL. International scholarship advances science and practice addressing bullying in schools. In: Handbook of bullying in schools: an international perspective. New York, NY: Routledge, 2010:1-6.

23. Marsh HW, Nagengast B, Morin AJS, et al. Construct validity of the multidimensional structure of bullying and victimization: an application of exploratory structural equation modeling. J Educ Psychol 2011;103:701-32.

24. Tremblay RE. Decade of behavior distinguished lecture: development of physical aggression during infancy. Infant Ment Health J 2004;25:399-407.

25. Verona E, Sadeh N, Case S, et al. Self-reported use of different forms of aggression in late adolescence and emerging adulthood. Assessment 2008;15:493-510.

26. Card NA, Stucky BD, Sawalan GM, et al. Direct and indirect aggression during childhood and adolescence: a meta-analytic review of gender differences, intercorrelations, and relations to maladjustment. Child Dev 2008;79:1185-229.

27. Marsee MA, Barry CT, Childs KK, et al. Assessing the forms and functions of aggression using self-report: factor structure and invariance of the Peer Conflict Scale in youths. Psychol Assess 2011;23:792-804.

28. Björkqvist K. Sex differences in physical, verbal, and indirect aggression: a review of recent research. Sex Roles 1994;30:177-88.

29. Feshbach ND. Sex differences in children's modes of aggressive responses toward outsiders. Merrill Palmer Q Behav Dev 1969;15:249-58.

30. Cairns RB, Cairns BD, Neckerman HJ, et al. Growth and aggression: 1. Childhood to early adolescence. Dev Psychol 1989;25:320-30.

31. Galen BR, Underwood M. A developmental investigation of social aggression among children. Dev Psychol 1997;33:589-600.

32. Crick NR, Grotpeter JK. Relational aggression, gender, and social-psychological adjustment. Child Dev 1995;66:710-22.

33. Desjardins T, Yeung Thompson RS, Sukhawathanakul P, et al. Factor structure of the Social Experience Questionnaire across time, sex, and grade among early elementary school children. Psychol Assess 2013;25:1058-68.

34. Gladden RM, Vivolo-Kantor AM, Hamburger ME, et al. Bullying surveillance among youths: uniform definitions for public health and recommended data elements, Version 1.0. Atlanta, GA: National Center for Injury Prevention and Control, Centers for Disease Control and Prevention and U.S. Department of Education, 2014. http://www.cdc.gov/violenceprevention/pdf/bullying-definitions-final-a. pdf (accessed 7 Sep 2015).

35. Finger LR, Yeung AS, Craven RG, et al. Adolescent peer relations instrument: assessment of its reliability and construct validity when used with upper primary students. Brisbane: Australian Association for Research in Education, 2008:9.

36. Fitzpatrick S, Bussey K. The development of the Social Bullying Involvement Scales. Aggress Behav 2011;37:177-92.

37. Schonert-Reichl KA, Stewart Lawlor M, Oberle E, et al. Identifying indicators and tools for measuring social and emotional healthy living: children ages 5 to 12 years. Ottawa, Ontario: University of British Columbia, 2009. http://educ.ubc.ca/research/ksr/ schonert-reichl.html\#scholarlypub (accessed 17 Mar 2012).

38. Fite PJ, Stauffacher K, Ostrov JM, et al. Replication and extension of Little et al.'s (2003) forms and functions of aggression measure. J Behav Dev 2008;32:238-42.

39. Connor DF. Aggression and antisocial behavior in children and adolescents: research and treatment. New York: The Guilford Press, 2002. http://books.google.com.au/books (accessed 13 Oct 2010)

40. Runions K. A multi-systematic school-based approach for addressing childhood aggression. Aust J Guid Couns 2008;18: 106-27.

41. Huitsing G, Snijders TA, Van Duijn MA, et al. Victims, bullies, and their defenders: a longitudinal study of the coevolution of positive and negative networks. Dev Psychopathol 2014;26:645-59.

42. Cross D, Waters S, Pearce N, et al. The Friendly Schools Friendly Families programme: three-year bullying behaviour outcomes in primary school children. Int J Educ Res 2012;53: 394-406.

43. Waasdorp TE, Bradshaw CP, Leaf PJ. The impact of schoolwide positive behavioral interventions and supports on bullying and pee rejection: a randomized controlled effectiveness trial. Arch Pediatr Adolesc Med 2012;166:149-56.

44. Scott JG, Moore SE, Sly PD, et al. Bullying in children and adolescents: a modifiable risk factor for mental illness. Aust N Z J Psychiatry 2014;48:209-12.

45. Vivolo-Kantor AM, Martell BN, Holland KM, et al. A systematic review and content analysis of bullying and cyber-bullying measurement strategies. Aggress Violent Behav 2014;19:423-34.

46. Hunter SC, Boyle JM, Warden D. Perceptions and correlates of peer-victimization and bullying. Br J Educ Psycho 2007;77:797-810.

47. Burns S, Maycock B, Cross D, et al. The power of peers: why some students bully others to conform. Qual Health Res 2008;18:1704-16.

48. Burns S, Maycock B, Cross D, et al. "Woodpushers are Gay": the role of provocation in bullying. Int $J$ Ment Health Promot 2008;10:41-51.

49. Olweus D. Understanding and researching bullying. In: Jimerson SR, Swearer SM, Espelage DL, eds. Handbook of bullying in schools: an international perspective. New York: Routledge, 2010:9-33.

50. Furlong MJ, Sharkey JD, Felix ED, et al. Bullying assessment: a call for increased precision of self-reporting procedures. In: Jimerson SR, Swearer SM, Espelage DL, eds. Handbook of bullying in 
schools: an international perspective. New York: Routledge, 2010. 329-46.

51. Gumpel TP. Behavioral disorders in the school participant roles and sub-roles in three types of school violence. J Emot Behav Disord 2008;16:145-62.

52. Young EL, Boye AE, Nelson DA. Relational aggression: understanding, identifying, and responding in schools. Psychol Sch 2006;43:297-312.

53. Bradshaw CP, Waasdorp TE, Johnson SL. Overlapping verbal, relational, physical, and electronic forms of bullying in adolescence: influence of school context. J Clin Child Adolesc Psychol 2015;44:494-508.

54. Schonert-Reichl KA, Guhn M, Gadermann AM, et al. Development and validation of the Middle Years Development Instrument (MDI): assessing children's well-being and assets across multiple contexts. Soc Indic Res 2013;114:345-69.

55. Gadermann AM, Guhn M, Zumbo BD. Investigating the substantive aspect of construct validity for the Satisfaction with Life Scale adapted for children: a focus on cognitive processes. Soc Indic Res 2011;100:37-60.

56. Troop-Gordon W, Gerardy H. Parents' beliefs about peer victimization and children's socio-emotional development. J App/ Dev Psychol 2012;33:40-52.

57. Bauman S, Del Rio A. Preservice teachers' responses to bullying scenarios: comparing physical, verbal, and relational Bullying. J Educ Psychol 2006;98:219-31.

58. Garandeau CF, Cillessen AHN. From indirect aggression to invisible aggression: a conceptual view on bullying and peer group manipulation. Aggress Violent Behav 2006;11:612-25.

59. Ostrov JM, Woods KE, Jansen EA, et al. An observational study of delivered and received aggression, gender, and social-psychological adjustment in preschool: "This White Crayon Doesn't Work..." Early Child Res Q 2004;19:355-71.

60. Elder GH. The life course as developmental theory. Child Dev 1998;69:1-12.

61. Nelson HJ, Kendall GE, Shields L. Neurological and biological foundations of children's social and emotional development: an integrated literature review. J Sch Nurs 2014;30:240-50

62. Jimerson SR, Huai N. International perspectives on bullying prevention and intervention. In: Jimerson SR, Swearer SM, Espelage DL, eds. Handbook of bullying in schools: an international perspective. New York: Routledge, 2010:571-92.

63. Lerner RM, Schmid Callina K. Relational developmental systems theories and the ecological validity of experimental designs. Hum Dev 2013:56:372-80.

64. ACARA. Guide to understanding ICSEA. 2012. http://www.acara. edu.au/verve/_resources/guide to understanding_icsea.pdf (accessed 27 May 2014)

65. Mustard JF. Early child development and experience-based brain development-the scientific underpinnings of the importance of early child development in a globalized world. The Canadian Institute for Advanced Research, 2006:74.
66. Adler N, Snibbe A. The role of psychosocial processes in explaining the gradient between socioeconomic status and health. Curr Dir Psychol Sci 2003;12:119-23.

67. Bronfenbrenner U, Morris PA. The bioecological model of human development. In: Damon W, Lerner RM, eds. Handbook of child psychology. Hobolen, New Jersey: John Wiley \& Sons Inc, 2006:793-828.

68. Morrow V, Richards $M$. The ethics of social research with children: an overview. Child Soc 1996;10:90-105.

69. Greene S, Hogan D, eds. Researching children's experience. London, England: SAGE Publications Ltd, 2005.

70. Liamputtong P, ed. Research methods in health: foundations for evidence-based practice. 2nd edn. South Melbourne, VIC: Oxford University Press South Melbourne, Victoria Oxford University Press, 2013.

71. DeVon HA, Block ME, Moyle-Wright P, et al. A psychometric toolbox for testing validity and reliability. J Nurs Scholarsh 2007;39:155-64.

72. Polit DF, Beck CT. The content validity index: are you sure you know what's being reported? Critique and recommendations. Res Nurs Health 2006;29:489-97.

73. Cole JCM, Cornell DG, Sheras P. Identification of school bullies by survey methods. Prof Sch Couns 2006;9:305-13.

74. Ahmad YS, Smith PK. Behavioural measures review No. 1: bullying in schools. Newsl Assoc Child Psychol 1994;12:26-7.

75. Rigby K. Bullying in schools and what to do about it. Australia: ACER Press, 2007.

76. Streiner DL, Norman GR. Health measurement scales: a practical guide to their development and use. 4th edn. New York: Oxford University Press, 2008.

77. Hogarty KY, Hines CV, Kromrey JD, et al. The quality of factor solutions in exploratory factor analysis: the influence of sample size, communality, and overdetermination. Educ Psychol Meas 2005;65:202-26.

78. ACARA. Guide to understanding 2012 Index of Community Socio-educational Advantage (ICSEA) values. 2013. http://www. myschool.edu.au

79. Trochim WMK, Donnelly JP. Research methods knowledge base. 3rd edn. USA: Atomic Dog, 2008.

80. Williams B, Brown T, Onsman A. Exploratory factor analysis: a five-step guide for novices. Australas J Paramed 2012;8:1-14.

81. Brown TA, Moore MT. Confirmatory factor analysis. In: Hoyle RH, ed. Handbook of structural equation modeling. New York: Guilford Press, 2012:361-79.

82. Allen P, Bennett K. PASW statistics by SPSS: a practical guide version 18. South Melbourne, Australia: Cengage Learning Australia Pty Limited, 2010

83. The National Health and Medical Research Council, the Australian Research Council and the Australian Vice-Chancellors' Committee. National statement on ethical conduct in human research. 2007. http://www.nhmrc.gov.au/_files_nhmrc/publications/attachments/e72 national_statement_march_2014_140331.pdf (accessed $18 \mathrm{Jul} 201 \overline{4}$ ). 